\title{
THE GREAT LAKES REGIONAL COLLEGE AS AN ENGINE FOR DEVELOPMENT: ITS IMPACT AND PROSPECT
}

\author{
Liang-Ling Kuo
}

Independent Researcher

\begin{abstract}
This study aims to investigate whether higher education can work as a vehicle of empowerment to eradicate poverty. It is based on fieldwork research at the Great Lakes Regional College (GLRC) in the Kanungu district of Uganda. The results depict a complex socio-economic image produced by poverty reduction policies. It is surprising, interrelated with various factors, and thus difficult to simply categorize as positive or negative. In the eyes of the institution's founder, achieving poverty relief with regard to alumni career development remains a significant challenge. In fact, the school's intended goal of creating a better future for college students is undermined by environmental constraints. With regard to the impact that the GLRC has had on the surrounding community since its establishment, this study's findings indicate that simply providing higher education is insufficient to achieve community development. However, the GLRC's role goes beyond that of a simple educational institution. Because it attracts an external population, the college serves as a multifunctional institution that triggers community changes at various levels. Taken together, this study offers potential directions for higher education institutions that target community development, and recommends a broad functional approach for such institutions.
\end{abstract}

Keywords: higher education, poverty reduction, community development, college impact

\section{Introduction}

Higher education's role in spurring economic development has recently come under the spotlight (Bloom, Canning and Chan, 2006). Substantial evidence and statistical data have demonstrated a positive correlation between higher education and macroeconomic development (Meulemeester and Rochat, 1995; Bloom, Canning and Chan, 2006; Obwona and Ssewanyana, 2007). Related studies based on numerical analyses are persuasive; however, since they tend to look at the macroscopic level, they lack detailed investigation of how individuals can change themselves and their surroundings through higher education. This report focuses on a study of the Great Lakes Regional College (GLRC), which was founded under a partnership with Volunteer Uganda and CHIFCOD (The Child to Family Community Development Organization). Both non-profit organizations cooperate to empower children and youth in the Kanungu district of Uganda through education in order to raise them out of poverty. Supported by Volunteer Uganda, this report aims to offer an understanding of how people can be inspired and motivated to bring benefits to the local community as well as earn higher education qualifications.

Situated in Krima subcounty of the Kanungu district in Uganda, the GLRC is an inter-denominational academic and vocational college established to deliver tertiary education that can effectively transform the local community. Currently, approximately 430 students aged 17 to 45 from western districts in Uganda like Kanungu, Rukungiri, Bushenyi, Kasese, Kabale, Kisoro, and Mbarara, are enrolled at the school. The GLRC offers multi-disciplinary courses including business, natural and social sciences, and education programs at the certificate, diploma, and degree level. Its various impacts in the ten years since its establishment reveal the institutional aspects of a higher education institution. 
This fieldwork sought to highlight the fact that a higher education institution can also be viewed as a multifaceted catalyst of broader development in the surrounding community, through impacts ranging from empowering people with knowledge and skills, creating businesses, and attracting an external population that boosts community dynamics. The findings of this research suggest that the development goals set by the GLRC are compromised by environmental limitations, indicating that a higher education institution simply offering education is not sufficient to achieve development in other areas. As shown in this case study of the GLRC, a higher education institution can operate in multiple dimensions to promote development. This implication informs recommendations for other higher education institutions to broaden their functions beyond merely teaching and learning.

\section{Research Methodology}

The qualitative data collected in this report was generated through semi-structured interview. Interview questions are shared in the appendix. Each respondent section is detailed below:

1. Current college students: This section focuses on the analysis of 22 interviews with college students, aged 18 to 30. The respondents included 5 women and 17 men; 17 were students in business administration programs, 2 were studying for a bachelor of arts in education, 2 were pursuing a degree in social work and social administration, and 1 was working toward a diploma in agriculture.

2. College alumni: Fifteen alumni participated in the research project. These participants were between 23 and 40 years of age and included 6 males and 9 females. Their backgrounds varied in disciplines and education levels. Their fields of study ranged from business administration, record management, education, social work and social administration to public administration. At the time of the interview, 3 were unemployed, 4 were self-employed, and the rest were employed by an employer. Their occupations included public servant, teacher, radio presenter, and accountant.

3. Community members: This section analyzes the interviews of 8 respondents from the extended community surrounding the institution. Research participants ranged from 28 to 50 years old and all were male. All of them had been living in the community for many years. Their occupations included GLRC college staff, technical teacher, health inspector, NGO worker, and church pastor.

\section{Literature Review}

The positive correlation between higher education and economic development has been proven in many quantitative studies (Bloom, Canning and Chan, 2006; Obwona and Ssewanyana, 2007; Kimenyi, 2011). All of these studies seek to examine the relationship between higher education and macroeconomic growth at the country level. As demonstrated by the econometric model developed by Bloom, Canning and Chan (2006) targeting Africa, higher education helps a country to catch up technologically, and enhances its ability to maximize economic output. To be more precise, increasing tertiary education stock by one year will result in a stable long-term $12 \%$ rise in the African GDP per capita. A case study conducted by Obwona and Ssewanyana (2007) suggests a positive link between student enrollment in public universities and GDP growth in Uganda. Kimenyi (2011) concludes that the divergence of income between African countries and their Asian and Latin American counterparts is partly due to different levels of enrollment in higher education. These studies have shed light on the importance and positive impacts of higher education on economic development. The results drawn from mathematical data analysis and presented in macroscopic indicators such as GDP and its growth rate are plausible, as they point out a clear relationship between two variables. Despite their strengths in clarity and simplicity, such research papers fall short in providing detailed explanations of the interaction dynamics between higher education institutions and the contexts within which they operate. For example, the specific role that the higher education institution plays in promoting economic development needs further investigation. 
Meanwhile, its potential and limitations have to be addressed in order to better understand the whole picture: how can and how should higher education encourage development?

Some studies have already uncovered interactive relationships between a higher education institution and the socio-economic environment where it is located. A causality analysis conducted by Meulemeester and Rochat (1995) affirms a positive link between national educational effort and economic development in four developed countries but fails to show this trend in Italy and Australia, indicating that higher education can only be effective in fostering development when certain environmental requirements are met. The authors propose that the content of teaching must be in accordance with the actual needs of the local economy. At the same time, the local socio-economic and technological threshold must be at the level needed to allow graduates to apply their knowledge. This finding is consistent with a case study based in Romania where the youth unemployment rate has increased in spite of higher education qualifications (Neamtu, 2015). Neamtu (2015) asserts that higher education has to be designed according to the real demands of the labor market. Otherwise, these well-educated human resources will remain underused and thus have no impact on economic development. Such studies deepen the discussion on the interaction between higher education and economic development by revealing the complexity of their relationship. It appears that higher education institutions need to work in coordination with the socio-economic structure with which they associate so as to successfully bring about improvements.

In this sense, a case study aiming at a single project or a higher education institution can probe into the topic at hand more deeply. In their research, Kruss et al. (2015) conclude that the "interactive capabilities" of a university in mediating its relationship with firms, sectoral intermediaries, government, and other knowledge producers is critical in driving economic development. The Square Kilometre Array project focusing on astronomy technology in South Africa achieved its success because of the excellent way that skills, knowledge, technologies, intermediaries, and funding worked together (Kruss et al., 2015). This case study stresses that the dynamics at different levels work in complicated ways to shape development possibilities (Kruss et al., 2015).

As discussed above, contextual factors and their interplay with higher education institutions have been highlighted through previous research. Correspondingly, the concept of "learning region", which describes the agency of a place to proactively respond to changing economies, emphasizes the vital role higher education institutions play during this process (Shaw and Allison, 2010). Under this framework, Shaw and Allison (2010) argue that universities are crucial actors in the transfer of knowledge from one group to another and create the learning system that propels economic development. The University of Sunshine Coast (USC) in Australia was the research target in their corresponding case study. The USC had been serving in a multifunctional role to empower the community. For example, it offered marine science courses tailored to local demands, conducted collaborative research with businesses and industries, and consulted with these community players regarding course development. The interactive relationship between the USC and the community ensured that the university best suited the local economic needs and therefore could enable community members to cooperate with businesses and industries in order to generate mutual benefits. The region itself is learning with the help of the USC, resulting in economic development from the perfect match between the supply and demand in human resources. In addition, the USC has created jobs by employing local architects in university design. The USC's case study shows that higher education institutions can work in various ways in relation to their local contexts to spur development, thus widening universities' potential for community development and informing further research on the detailed dynamics between the two.

The diverse variables in the relationship between a higher education institution and its hosting environment inevitably invites challenges caused by conflicting roles amid different missions, as reflected in some case studies (Aligaweesa, 1987; Lazzeretti and Tavoletti, 2005). Aligaweesa (1987) notes that the Makerere University in Uganda has been struggling between two contradictory paths: fulfilling the traditional educational role to transmit academic knowledge, and attempting to be relevant to rural development as to address local needs. This tension casts uncertainty on its direction. It remains difficult for the university to strike a balance 
between universal scholarship and the demand for relevance to the Ugandan situation. Moreover, the plurality of the university community makes it difficult to reach consensus over curriculum adjustments. In actuality, little adaptation of course programs has been made to increase the university's relevance to its local context. Conversely, the University of Twente in the Netherlands represents a successful example in which the higher education institution effectively plays multiple roles at the same time (Lazzeretti and Tavoletti, 2005). The university adopts the concept of "entrepreneurial universities" proposed by Clark (1998) and proves that local economic relevance and international academic excellence are not mutually exclusive features (Lazzeretti and Tavoletti, 2005). Defined by Clark (1998), an entrepreneurial university is good at expanding a developmental periphery, establishing a diversified funding base, and stimulating an academic heartland. Practically speaking, the University of Twente is financed by various funding sources and has built up a network with many spin-off companies so as to solidify its role in maintaining mutually beneficial relations between the university and the regional economy. The stable funding allows the university to implement research at an international standard and achieve a good academic reputation in certain fields like strategic science. Additionally, the university serves as a consultant and mentor to start-ups and spin-off companies by providing professional knowledge to support their operations. These companies in turn employ the students from the university. The entrepreneurial approach undertaken by the University of Twente expands the dimensions in which a university can have influence, making it a business driver in the region. Its entrepreneurial vision is the key factor enabling it to be a regional development booster. Although Makerere University and the University of Twente provide differing examples of how higher education institutions strive to balance different roles, their results suggest that inherent structural barriers can be impediments to success. However, the challenges can be resolved through innovative strategies, which require a new set of knowledge.

Many studies indicate a close link between higher education, technological innovation, and improvements in R\&D capabilities (Porter et al., 2002; Lederman and Maloney, 2003; King, 2004; Lin, 2004). The knowledge generation effect is clearly addressed in these studies. From this perspective, higher education is the catalyst in transforming developing economies into capable actors that grow and prosper independently as they become able to produce knowledge based on existing conditions and future goals. The impact is long lasting as a result of the acquired agency in self-learning and creativity to spark positive change; therefore, sustainable development becomes possible.

Summarizing the literature above, higher education institutions are generally impactful in expediting economic development despite varying scenarios illustrated in every case study. In reality, many factors at different levels of scale are involved in the complicated dynamics by which higher education institutions operate as multifunctional institutions to coordinate every element of a network efficiently in order to drive development. The interactions connecting each part in the economic system and adaptability to local needs have been shown to be critical factors in this process. Nevertheless, challenges that arise from complex aims can drag down development when higher education institutions fail to appropriately balance conflicting roles. In sum, higher education can only be effective in promoting development when it is well embedded within the local context.

\section{Analysis of Semi-Structured Interviews}

\section{Feedback from Current College Students}

\section{The Secular View of Education}

There is a clear consensus among respondents who are currently in college that education is impactful and positive in changing people's futures. Going further, this belief appears to stretch beyond these students to the people in their circles as many reply that they have been told about the importance and advantages of education. Encouraged by their parents or older relatives to enroll in college, many of them are supported financially by their families. Based on this observation, it is obvious that the perception of pursuing education as a way to improve one's standard of living has been deeply rooted in the community. This belief is repeatedly expressed 
throughout the interviews, with one student even stressing that "If you are not educated in Uganda, you are nothing."

Though respondents mention changes that education has brought about in their thinking capacities, the secular view of education dominates as respondents address it much more strongly. Almost all respondents state that education is a powerful tool in facilitating social mobility, especially in terms of monetary status. They interpret education from an economic perspective with focuses on employment and income. That is, they share the view that being well educated is a guarantee of a better future in which they can get better jobs, defined by higher salaries and social status, and thus they can become self-reliant. In most cases, these students want to become accountants. Accounting is a popular job in the extended community around the GLRC because of the steady income and reasonable working hours it offers. However, some respondents say that education equips them with knowledge and skills to start self-owned businesses by which they can become wealthier. This finding may be biased because the majority of respondents were studying in the business department at the GLRC. However, as business department students constitute around $65 \%$ of the college population, the view provided by these study participants can be interpreted as the mainstream opinion in this school, confirming that business studies are popularly perceived as a way to improve one's finances and achieve upward mobility in life.

The majority of the community around the Great Lakes Regional College earns a livelihood through agricultural activities that demands intensive labor but does not guarantee a stable income. Enrolling in higher education is considered a means to escape from such living conditions.

When it comes to how education can improve respondents' futures, a common answer is that the college teaches the entrepreneurial knowledge and skills to start a business through which they can become self-sufficient. The business plans among students seem to be fairly identical. Most respondents who were interested in establishing their own businesses already had an idea in mind; for example, running a retail shop was seen as an ideal choice. Different options like operating an animal husbandry business or restaurant were rarely voiced. These kinds of businesses mirror the most frequently spotted businesses in the surrounding community. Normally they are profit-oriented and sell similar commodities to each other, sharing the market within the limited local population.

Across the interviews education is perceived in an instrumental way as a means to become employed and wealthy. In fact, few respondents talked about their genuine interests in learning subjects like accounting and finance. Most of them had entered these programs because of the availability of jobs associated with their qualifications. Education is presented as a strategic ladder toward a better life instead of an inspirational contributor to self-growth and maturity. In a nutshell, education is simply related to terminating poverty through its function to support students' ability to find employment, earn money, or start their own businesses.

Certainly, education about social responsibility or creativity in business strategy is omitted in the GLRC's course design. Except for one respondent, all of the students interviewed were studying for the sole purpose of ameliorating their own problems without considering the positive influence a businessperson could have on the community. The business ideas students produced seem to copy common businesses in the surrounding area. Their plans center mainly on retail businesses, which means selling products already available in the local shops. Such businesses serve only to segment the market. This reveals a gap within the college education as the GLRC aims to cultivate community transformers who are creative and able to innovate. Accordingly, the concept of social enterprise whereby both the entrepreneur and community can mutually benefit needs to come into play to inspire students to think about possibilities to improve the local economy as well as drive community development. Moreover, GLRC must provide courses relevant to the local context if students are expected to become active agents in transforming the community. The current college curriculum seems to ignore the reality of the local economy, instead emphasizing general knowledge about running small-scale business that would have a limited impact on emancipating the community from economic stagnation. 


\section{Social Respect}

Some respondents talked about becoming more respected by others in the community after enrolling in the college. People see them as more intelligent individuals who have a higher standing. It is common for welleducated people to be approached by the masses for advice and guidance, as described in the student testimony below:

I started to be a counsellor...... had a lot of my lives in custody...... Because I am educated, I can be expected to be a leader, either in politics as the village level or in some organizations. You have a big role to play as an educated person.

The popularity and influence of educated people within the local community indicate a clear divide that exists in the public's attitude toward individuals with different levels of education. This implies that the community members value education. They appreciate the knowledge and skills acquired in school and regard them as correct guidelines. The community perceives that education is something beneficial that can change their lives. Based on this observation, the interplay between the college and the community is promising because the institution is working with people who appreciate its existence.

\section{Future Projections}

Most students have clear visions for their futures. Their plans include being employed, starting businesses, and advancing to higher education. When talking about the future, they feel confident and optimistic about concrete objectives. Clearly, they believe that education has positioned them along a predicable track of progress in contrast with an idle life that lacks any effort or chance of improvement.

Despite differences in their responses about future planning, these students have a clear concept of "future", in which they can work hard and then achieve goals. With such awareness that they can become agents of change and take initiative to direct their careers, they can escape impoverishment. Although this line of thinking is not directly taught by any course, the education presents some potential paths to them and inspires students to conceive their own plans. Moreover, students gain the capacity to predict the outcomes of different actions. By assessing current conditions and pros and cons of each decision, they can avoid getting caught in unfortunate predicaments. In conclusion, their education has empowered them with the skills to be self-motivated, and placed them at the start of a road to brilliant futures.

\section{College Alumni Testimony}

\section{Job Searching}

The first challenge GLRC students face after graduation is the search for a job. This reality may not be as positive as alumni might have expected. In fact, three alumni who participated in the interviews were unemployed. Some respondents disclosed that the qualifications they had earned from a bachelor degree were not sufficient to guarantee employment upon graduation:

Below, one alumna with a diploma shares her view on the chances of getting a job after graduation, as well as the motivation to achieve an even higher level of education:

The difficulty we are getting here, diploma it is not enough. So we continue studying to reach the higher level, we get bachelors and masters.

We are in a competitive world, everyone has studied, everyone has gone to school, so it become hard. For $m e$, and you, and other person, looking for one job. Of course they can't employ all of you....... 
She then moved on to talk about classmates who were unemployed and desperate for jobs: They are still finding, they are calling me "can you find me some jobs?"

Correspondingly, it can be seen that a diploma is not considered valuable in the public sector:

You can't get a better job with a diploma.....In fact the repeated restructuring is coming within government institution in district...... You find those who have diploma they tell you go for a degree...... when you don't have money to go for a degree they restructure you and you go out of the system.

Based on the responses above, one regarding the private sector and the other the public sector, there is an obvious oversupply of post-secondary educated graduates. In other words, employers do not appreciate any qualifications below the bachelor level. As the number of people with post-secondary qualifications has increased, the value of their education has decreased on the demand side. Meanwhile, this has caused the degree holders to stand out amongst the candidate pool, making them perfect fits for rare jobs available in the community. Even though graduates who have earned certificates and diplomas are better educated than they previously were, they may end up caught between struggling to secure formal jobs or living like uneducated neighbors as peasants or housewives.

Connections are the deciding factor in whether or not a graduate gets a job. Information about job openings is shared only between people who know each other. Because there are no official or public hiring channels like job websites or bulletin boards with applications and interviews to follow, graduates who lack such information channels are likely to be excluded from employment opportunities. Although some alumni do send in applications and go through interviews, they initially learn about those job openings from their acquaintances.

An alumni describes these connections below:

One might not know me, but knows my dad, or knows my grandfather, or knows my uncle, or knows my sister. So one will give you a job because something connects you to that person, that is very common here, actually that is the most thing it does.

He then talked about somebody he knew who searched for a job for seven years after finishing a bachelor degree in the college.

This phenomenon was further confirmed by an unemployed alumni who had a certificate in business administration. She described the process she was using to find a job: "I haven't applied but my friends are trying for me. They are trying for me where they work."

Besides the networks at hand, proof of educational qualifications also matter. As told by two alumni: "You still need to have qualifications, it's not all about just going." "When you apply the job, they need to receive original documents." From the interviews, two critical factors that dominate the job search can be identified in this community: connections and the evidence of a good education. Wherever these two coexist, obtaining a job become possible.

\section{The Financial Burden}

Most alumni who were employed reported they were not happy with their current situations. These feelings primarily derived from dissatisfaction with their income, or feelings of being overwhelmed by many required expenditures that drained their earnings. The related difficulties even prevented them from pursuing future goals.

This situation was exemplified by the words of one of the respondents: 
We wish to go for further study, but of course you see that income we are getting here does not help us to go for that side, degree. Because I have a family and I am earning 200 thousands (equivalent to 50 pounds) so I can not pay tuition for bachelor degree.

Someone who possesses a rarely seen bachelor degree in this community is expected to lead a decently comfortable life. However, one of the alumni disproves this notion in his interview. As a secondary school teacher he earns a monthly income of 500 thousand Ugandan shillings, which is much higher than the average. However, he continues to struggle:

It's not enough. I have dependents. I have parents......My in-laws and my brothers and sisters and the elders...I have to look after them...therefore I have the debt burden.

A respondent with a bachelor degree in social work and social administration said the same thing, although she currently has a job in the district government as a community development officer and earns 800 thousand Ugandan shillings per month:

I can not say I am satisfied because... it can not be enough for my family because I have other siblings, I have other children who I am looking after.

In truth, the monthly incomes of these two respondents were the second and third highest among all of the interview participants. Their descriptions of financial stress were surprising given that the attainment of a bachelor degree is typically associated with an affluent life in the community. This is not to conclude that higher education is completely useless in improving students' quality of life. However, these comments from alumni speak to the fact that some background constraints limit the impact of the GLPC in improving the financial conditions of its graduates. The general level of poverty and unemployment in the community force those who are well educated and have jobs to shoulder the responsibility of supporting family members. Such burdens eat up their salaries.

Though some alumni are able to save up to thirty percent of their income, most alumni's monthly savings do not exceed 50 thousand Ugandan shillings, which equates to approximately twelve pounds. Their situations reveal that the local economy fails to grant well-educated alumni the affluence expected by themselves and the local society. In comparison to the public respect that educated people gain from the community, their financial conditions can be interpreted as underperforming relative to local commodity prices. Indeed, this trend reflects the local salary level, which is interwoven with the area's economic development stage, and which should also be assessed and tackled by the college as it aims to alleviate poverty through higher education.

\section{Positive Opinions}

Apart from these disappointments, these alumni refer to some advantages and positive impacts from their education as well. For example, they admit that it is impossible to get a "formal" job, which involves working indoors and is less labor-intensive, without the qualification of higher education. Obviously, higher education still serves as the ticket to employment, though other factors like networking play a role. Also, alumni who have chosen to be self-employed agree that their education has taught them the know-how to run a business. Female alumnae are inclined to stress that their education has helped their confidence and empowered them with the knowledge and skills to be financially independent. Their responses imply that education frees them from being engaged to be married at early age during which women usually concentrate on household affairs and rely on their husbands economically.

The women express a further positive aspect of their college education that specifically benefits females. Girls who do not enter higher education are very likely to be married at a young age in this community. Thereafter, they become housewives confined in the household. Higher education provides them with alternatives: they can 
have their own careers or find independence at home if they have to meet traditional expectations and do not find the workplace to be friendly.

One woman who has a diploma in business administration said the education enabled her to be self-employed as staying at home was preferred by her husband and working outside was considered unsafe. In short, higher education helps to reduce the gender inequality to some extent by empowering women. This issue requires further research and investigation.

\section{Perspectives of Community Members}

\section{Business Generation}

The business generation effect directly resulting from the GLRC is very significant. It is even reflected physically in the landscape changes around the college. As noted by the community respondents, most businesses surrounding the college were built after its establishment. The types of businesses are quite diverse to accommodate all the basic needs of the students living there. The influx of students provides a market for local businesses and brings a flow of capital that benefits the community. The drastically increased land value supports this assertion, as it manifests the high demand for commercial property, and implies the popularity and potential of the market generated by the college.

\section{The Great Lakes Regional College}

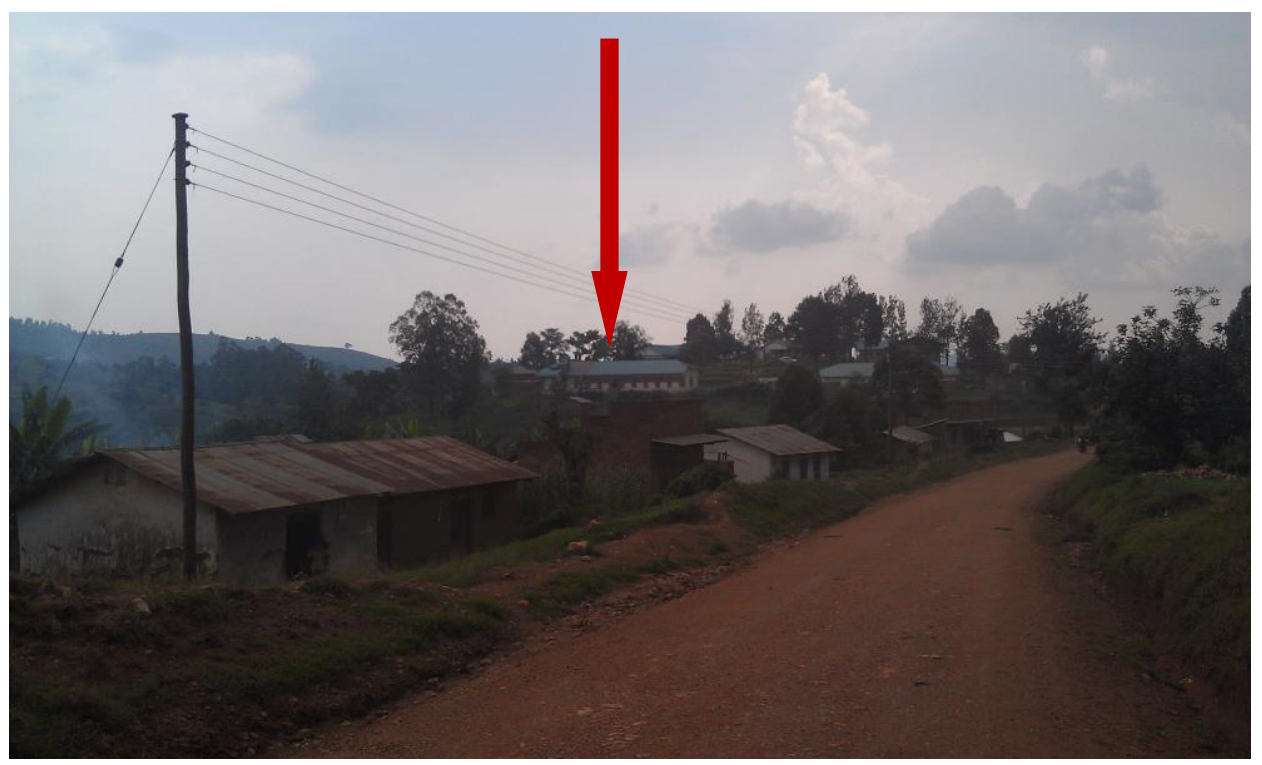

Figure 1: Houses have been built around the college 


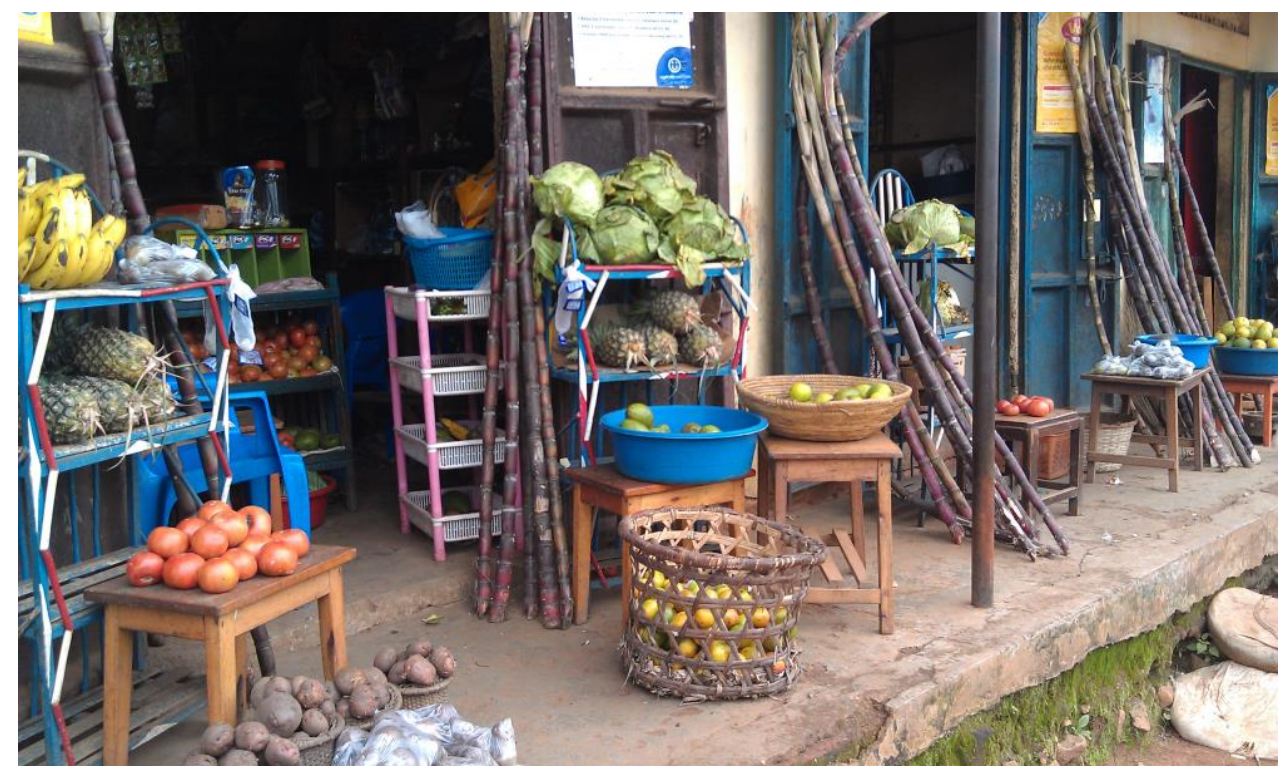

Figure 2: Local peasants now have a market to sell their products

In general, these business generation effects are caused by the incoming population from outside towns. This new population is composed of people who can afford tuition and living expenses, so they introduce external capital into the community, thus stimulating and energizing the local economy. In the area around the college, the majority of locals are peasants whose livelihood depends on manual agricultural production. The newly emerging population gives these peasants additional income by purchasing their agricultural products at grocery stores and meals made from them in restaurants. They may not buy the food directly from the peasants, but they significantly increase demand for the food. This helps the peasants earn more because they now have a market base and can serve as upstream suppliers. Even the college itself has to buy a large quantity of agricultural products from local peasants in order to provide regular meals to staff and boarding students. Aside from agriculture, many types of businesses like salon and retail shops have begun to spring up to target the incoming population. Without a doubt, the college, as an institution that brings people into the community, has contributed to the local economy by increasing the population and demand for goods and services.

\section{Demographic Shift}

Because the college has attracted an external population to the community in the form of students and foreign volunteers, important social changes have taken place in the area. People in the community have connected with people from other towns, and even other countries. They have started to acquaint themselves and build relationships with these outsiders.

The community is now exposed to the outside world. It was originally isolated to some extent due to the poor transportation network and its distance from the central part of the country. The college can thus be seen as a mediator between the community and the outsiders. This institutional role can be a double-edged sword. On the positive side, the college has the potential to alleviate the isolation of this community and thus facilitate its economic development. If the community can take advantage of the connections with the outside world, many development opportunities provided by the new external population, such as project interventions, job recruitment and agricultural trade, will become possible. Since the community is situated in a very rural part of the country and has little exposure to the outside, the college should serve as an important coordinator that mediates the relationship between the community and the external people, identifying cooperation opportunities that will benefit the locals. On the negative side, the incoming population has caused some problems that annoy local residents. These are described in the following section. 


\section{Negative Impacts}

There have been various impacts stemming from youth and foreigners flocking into the community from outside. These people have brought changes to community dynamics in terms of culture and interpersonal relationships, and unfortunately, community members perceive most of these shifts negatively. These phenomena are worth paying attention to because they may lead to serious social problems like the spread of HIV or mistrust between incoming students and locals. In the long run, these problems are likely to hinder the development impact the college aspires to make. The community feedback contained herein should motivate the college to seriously examine the effects of attracting outsiders and construct proper strategies to smoothly integrate the population in a way that is beneficial for local development.

Most concerns expressed by community members revolve around unrestricted sexual behaviors among students, or between students and community members. Associated problems include the spread of sexually transmitted diseases, early pregnancy and abortions, and an increased divorce rate. All of these trends have incurred many negative feelings and complaints about the college. Some locals even think the college is completely "bad". Below is one testimony offered by a local resident who has been living in the community for many years:

You find people have divorced their wives just because they now get into relationships with the students of the college... and then you are looking at how the community perceives education, try to say it's a lot of misbehaviors...interpretation of the community is like that.

Because the college sometimes invites foreign volunteers and researchers into the community, foreign cultures, usually western ones, have been influencing the local people as well. This impact is especially observable among the youth. However, some of these influences are regarded as offensive to local customs. These issues emerge in the experience shared by one local man, who notes that there were few foreign visitors to the community before the founding of the GLRC:

For example, other culture, they may accept people to put tattoos on their bodies, and most of the students here, they put tattoos on their bodies. It did not happen. Because of the influence of the people that come from western cultures, that would be a negative impact..... Before, it was a shame in the community for a lady to put on a miniskirt.

As one can see from the description above, the import of western culture is deemed a cultural invasion that weakens the local tradition. Such concerns cast doubt on the relationship between the community and incoming visitors. Because the community has just started to be in contact with external people since the establishment of the college ten years ago, transformation from a closed society to one that welcomes foreigners would be significant and would require discretionary policies to address related issues like how to properly introduce different cultures in order to build positive relationships that encourage mutual trust and community development. Any attribution of cultural offense to the college will certainly impede its efforts to promote community development. Thus, the college, as the main importer of foreigners, should play a major part in related research and practice at this beginning stage of the community's opening.

\section{Conclusion}

Overall, the GLRC has brought about community development to some extent, though development has been accompanied by some negative effects and leaves room for improvement. The locals are genuinely appreciative of the school's provision of higher education at lower prices at which payment installment plans are possible. Both youth and employed adults have acquired knowledge and skills from the college, which has empowered them to reach goals like running their own businesses, and equipped them with professional expertise in community development. At a personal level, these well-educated students and alumni have capabilities that place them at a starting point from which they can produce change. For example, they plan for the future, think 
analytically, and have a good command of English that helps them connect with the outside world. Furthermore, as some students are interested in or have devoted themselves to development either by creating a business or operating projects, their impact benefits the whole community. The existence of the GLRC and associated influences have also raised awareness within the community of the importance of higher education.

In spite of the college's ambition to change the futures of students, the GLRC's effect remains tempered, even limited due to the environmental constraints. The reality uncovered from interviews with alumni clearly clashed with the expectations held by current students. This contradiction highlights the challenges of the college and suggests more work is required to enhance development. The geographical isolation of the community and the nascent local economic development offer few job opportunities, low salary, and many unemployed dependents. Though some alumni manage to save a regular amount every month, many find it hard to make ends meet. The scarcity of the "clean collar" jobs that educated people aim for make degrees and educational qualifications very important, while personal connections are vital assets to stand out among the workforce competition. In spite of facing continued financial challenges after graduation, all alumni agree that their college education has lifted their quality of life to some degree, and most earn a steady income.

The GLRC also contributes to the community by attracting an external population and creating employment. The former has an enormous impact on the local economy as these newcomers are relatively affluent compared to local peasants. They have become house tenants, the market base for agricultural products and retail shops. As the college has been operational for ten years and many businesses have already been established around campus, it is worth investigating whether this impact has topped out, or whether growth potential still exists. The influx of newcomers has caused negative impacts as well. The incoming population has changed the social and cultural dynamics in the community, resulting in serious problems like the spread of sexually transmitted diseases and early pregnancies.

This case study of the GLRC sheds light on how a higher education institution may operate at various levels to influence the community, and how it can adapt to enhance its impact on community development. From the experiences of the GLRC, it can be deduced that a higher education institution can work in different dimensions to impact its surroundings, especially when the community was previously isolated with little exposure to the outside world. Although the school has successfully introduced economic benefits into the community, persisting economic underdevelopment due to the county's remote location remains a big hindrance to community development. The GLRC must therefore continue serving a multifunctional role to engage with many facets of community life. For example, it needs to coordinate the community's relationships with the outside so as to bring in more interventions and opportunities. The college should also increase its emphasis on social responsibility in the course design and educate community members through agricultural projects and literacy programs. The implementation of such recommendations could serve to help the GLRC achieve its mission of raising the local community out of poverty through sustainable community development.

\section{References}

Aligaweesa, M. A. K. (1987) The role of a university in national development: a case study of Makerere University. The Journal of Educational Administration, 25(2), 294-307.

Bloom, D., Canning, D. and Chan, K. (2006) Higher Education and Economic Development in Africa. Washington, D.C.: World Bank.

Clark, B. (1998) Creating Entrepreneurial Universities, Organizational Pathways of Transformation. Oxford: Elsevier Science for the International Universities Association Press Pergamon.

Kimenyi, M.S. (2011) Contribution of higher education to economic development: a survey of international evidence. Journal of African Economies, 20(3), 14-49.

King, D. (2004) The scientific impact of nations: what different countries get for their research spending. Nature, 430, 311-317. 
Kruss, G., McGrath, S., Petersen, I. and Gastrow M. (2015) Higher education and economic development: the importance of building technological capabilities. International Journal of Educational Development, 43, $22-31$.

Lazzeretti, L. and Tavoletti, E. (2005) Higher education excellence and local economic development: the case of the entrepreneurial university of Twente. European Planning Studies, 13(3), 475-493.

Lederman, D. and Maloney, W.F. (2003) R\&D and Development, Policy Research Working Paper 3024: Washington, D.C.: World Bank.

Lin, T. (2004) The role of higher education in economic development: an empirical study of Taiwan case. Journal of Asian Economics, 15, 355-371.

De Meulemeester, J. and Rochat, D. (1995) A causality analysis of the link between higher education and economic development. Economics of Education Review, 14 (4), 351-361.

Neamtu, D. M. (2015) Education, the economic development pillar. Procedia - Social and Behavioral Sciences, $180,413-420$.

Obwona, M. and Ssewanyana, S. N. (2007) Development impact of higher education in Africa: the case of Uganda. Kampala: Economic Policy Research Centre. [Research Series No. 48]

Porter, M. E., Sachs, J. D., Cornelius, P.K., McArthur, J.W. and Schwab, K. (2002) The Global Competitiveness Report: 2001-2002. Geneva: World Economic Forum.

Shaw, J.K. and Allison, J. (1999) The intersection of the learning region and local and regional economic development: analysing the role of higher education. Regional Studies, 33(9), 896-902. 